to serve our fellows, to defer their doom by kind offices and select none even for the value of their lives. The tradesman, the landlord and all who gain a livlihood out of the necessities of others, may flourish under the egis of the law, but preferably not ourselves, for legislation knows but one remedy, that of a different and leveling method. It takes care to spread only on the thin slice. Much toil and much selfconquest is the screed of our book of fate. Let us read it with a contrite submission and like the begarar in the market place wait until the pittance grows into an investment.

It is not for us to waste life in banquet halls with well-rehearsed laughter and invite placid slumber to the sound of the lute. Reverently, our kingdom is not of this world, for though art may make the Sybarite, science never, and "then too," rejoins the cynic, "there may be no more sleep upon a bed of down than upon a pallet of straw, no more content with millions than the frugal meal with much liberty." "Anyhow," continues a modern Diogenes, "we could much better enjoy our outing were it not for that ponderous book of questions so pompously borne in our rear."

\section{THE PATHOGENESIS OF LOCOMOTOR} ATAXIA.

Presented to the Section on Neurology and Medical Jurisprudence, at the Forty-eighth Annual Meeting of the American Medical Association held at Philadelphia, Pa., June 1-4, 1897.

BY L. HARRISON METTLER, A.M., M.D. 'CHICAGO, ILI,

The gradual attainment of our present knowledge of the disease known as locomotor ataxia, is one of the fascinating stories of medicine. While it is undoubtedly true, as one writer says, that it is the most common and the best known today of all the nervous affections, and while it is also true that the advances made toward the recent conception of its etiology and pathology have within the last few years been something marvelous, it is nevertheless a fact that after all we have only entered upon its elucidation. Many of the newer discoveries have only added to the complexity of our knowledge. We are almost as much in the dark as ever in regard to the real cause or causes of the trouble, nor have we found as yet any sufficient reason why those causes should exert a selective action upon special nerve areas. One comprehensive definition has it that locomotor ataxia is a degenerative sclerosis of the sensory apparatus, involving this side of the nervous system anywhere from periphery to cortex. But why should the sensory elements be the subject of deleterious influences in this disease more than the motor elements which lie in such close proximity to them, and which so far as we can see are histologically identical? There must be a reason for this, and it is the object of pathology to discover it. In regard to the differences between sensory and motor elements, anatomy is silent and physiology only declares that one is centripetal and the other is centrifugal in function. Even should some agreement be arrived at in regard to the character of the lesion in all cases, whether it is inflammatory, degenerative, interstitial or parenchymatous; and even should a happy conclusion be reached in regard to the much vexed question of etiology, whether it is syphilitic, traumatic, hereditary, sexual, etc., the all important contention still remains as to why these causes should always produce the degeneration, the sclerosis or the inflammation of the sensory elements as they always do in locomotor ataxia. To be sure they often give rise to similar lesions in other parts of the nervous system, but still they must possess some special influence in locomotor ataxia, since this disease is so much more common than all the other nervous diseases. When one attempts to extensively examine the literature on this subject he is soon overwhelmed with confusion; for he observes that almost every writer promulgates a theory of his own, based largely upon facts and observations interpreted in accordance with his own mental bias and limited experience.

Consider for a moment the etiology of the disease. Syphilis has been assigned as a cause of locomotor ataxia in from 5 to 90 per cent. of all cases, and by equally competent authorities. When in 1876 Fournier irst called attention to the wide association of syphilis and tabes, he was severely criticized because his field of observation was chiefly among syphilitics. But Duchenne, who first named and described the disease in 1864 , so that it was thereafter given a place by itself in the text-books, indicated his suspicions of its specific nature by urging the efficacy of the iodid of potash in its treatment. Testimony has been steadily accumulating in favor of the tremendous influence of syphilis as a causative factor until at the present time there is not wanting high authority for the assertion that locomotor ataxia is nothing more nor less than a sequel of lues, and that the cachexia venerea constitutes the background whereon all cases are projected, no matter what may be the exciting cause that starts them into activity.

Möbius of Leipzig declares that tabes is a syphilitic disease. Darkschewitsch of Kazan argues that syphilis must be considered as the cause of the disease because the specific peripheral neuritis (toxic polyneuritis) is the primary trouble, the cord lesion being merely a subsequent secondary manifestation. Blathner of Berlin, points out a sort of crossed action of syphilis in tabes, as revealed in the not infrequent insufficiency of the aortic valves. It is to be noted, however, that though Gowers states that valvular heart disease "is the most important" complication of tabes outside of the nervous system, it has been shown, after a careful study of the question by Bailey, that "while organic cardiac changes occur in a small proportion of cases, their occurrence is not more common in tabes than in any other disease of a senile character." Minor of Moscow, brings forth apparently some strong proof of the syphilitic origin of locomotor ataxia upon ethnographic grounds. Out of a series of 1642 cases of nervous diseases of all kinds among the native Russians, 496 were males and 264 females, while among the Jews, 449 were males and 433 females. Of the male Russians, 25 per cent. were syphilitic; of the females, 11,4 per cent. Of the male Jews, on the other hand, only 7 per cent. were syphilitic, while of the females only 1.5 per cent. had had syphilis. It is strikingly significant, therefore as bearing upon the question of the syphilitic origin of tabes, to find that the latter disease is five times more frequent among the Russians than among the Jews. But note in connection with this the equally significant fact, long ago pointed out by Grimm, that syphilis is particularly rife in Japan, while tabes is exceedingly rare.

Of 1016 optic nerve atrophies examined by Galezowski, 800 were found in tabetic subjects, and more than half of these were syphilitic. In Schwarz's tabulated list of thirty cases of tabes, all were syphilitic. Germeix 
insists that syphilis is the cause of locomotor ataxia. Strümpell holds that all cases are due to syphilis, the lesion not being, however, strictly syphilitic, but rather a metamorphosis brought about by the slow selective action of the toxin. Vermel voices the same opinion, as likewise does Raymond of Paris. Erb's recent list of 500 cases of tabes admitted syphilis in 89.2 per cent., but Erb recognizes the power of other causes acting in conjunction with syphilis, for he enumerates a long and varied list of such causes. Specific disease was found to have been present in 90 per cent. of the 400 cases of Gajkiewicz of Warsaw. Marie of Paris, a pupil of Charcot. who was notoriously conservative in regard to the influence of syphilis, has lately declared that syphilis is practically the only cause of tabes. Truly does experience teach men different lessons!

One fact is certain, however, that syphilis has not yet been established as the only cause of locomotor ataxia. Many advocates of the specific etiology of the disease are forced to admit that there are some cases in which syphilis does not seem to play a rôle. Soon after Fournier had announced his radical views, Teissier of Lyon, took the stand that lues was not a direct, competent cause of posterior spinal sclerosis, though he ranked it as a predisposing cause along with gout, rheumatism, alcoholism, etc. He based his views upon some thirty-five cases, of which only thirteen were positively syphilitic. In 1887 Karger of Berlin, reported that 53 per cent. of 117 cases of tabes were syphilitic. In the same year Nägeli of Zurich studied a list of 1403 cases, and found that 46.1 per cent. were positively syphilitic, while 60.6 per cent. were merely suspiciously so. Gerlach observed among 156 cases of tabes, that 56.25 per cent. of the men and 66.7 per cent. of the women were the victims of specific disease. In contrast with Gerlach's observation it is interesting to note that Andronico examined "great numbers" of prostitutes, of which many must doubtless have had syphilis, but found that locomotor ataxia was exceedingly rare among them. It is currently stated that tabes affects men in proportion to women as ten to one, and all because women are less exposed to the same deleterious influences that men are. But if syphilis be the direct cause of tabes the ratio, it seems, ought to be less that ten to one, even taking into consideration the well known fact that syphilis is not so disastrous to the female as to the male. In six of Andronico's cases, all of which were women, only one had had syphilis. At all events, this disparity between men and women in regard to syphilis and its relation to locomotor ataxia, would seem to indicate that syphilis is not a direct cause of the latter disease, but rather a predisposing or diathetic cause; and that the singular immunity of women is due to their comparative freedom from the direct, exciting causes such as cold, damp, muscular exertion, etc.

That syphilis can not be the only cause of locomotor ataxia is conclusively shown by the case of Leloir, which became a victim of the spinal disease in 1878, and not until five years later, in 1883, was afflicted with syphilis. Bernhardt and Guelliot have both reported cases of tabes, free from specific disease, in which the excessive muscular exertion of running a sewing machine seems to have been the only cause.

Lagondaky estimates that only about 42 per cent. of tabetics have been the victims of syphilis. Kuhn, of the Berlin Charity Hospital, found that syphilis was present positively in only about 37 per cent. of the tabetics, probably in 31 , and possibly in 7 per cent.
In 225 cases of the disease, Pitres of Bordeaux could only prove that 55 per cent. of them had been syphilitic. Since there were other causes in operation at the same time, such as heredity, alcoholism, sexual excesses, etc., the syphilitic cases, pure and simple, were reduced to 22.33 per cent. Leyden is still of the opinion that 20 per cent. represents a fair estimate in regard to the number of cases of tabes caused by syphilis. Of 108 cases quoted by Storbeck, 20.4 per cent. were syphilitic, and 58.3 per cent. were non-syphilitic. After all, it would seem as Cardarelli says, that the effect of syphilis in the production of locomotor ataxia has been greatly overestimated.

In a certain percentage of cases the syphilitic toxin may so impair the nervous tissues as to cause them, under some special stimulation, to undergo degeneration and sclerosis. There must be some exciting cause, some determining cause to act upon the general cachectic state produced by the syphilitic toxin, or else it will be incumbent upon the advocates of the syphilitic etiology, such as Marie, to explain, first, why all or at least a larger percentage of syphilitics do not contract posterior spinal sclerosis, and secondly, why this universal wide-spread toxin floating through the blood, selects special parts of the nervous system whereon to expend its force. They must demonstrate a selective power in the toxin or a special susceptibility in the sensory apparatus. Until such an explanation is forthcoming other causes must also be invoked. Among these there have been enumerated heredity, age, sex, cold and damp, sexual excesses, trauma, alcoholism, ergotism, arsenicism, environment and other spinal diseases.

Let us now look at the question from the pathologic side. Locomotor ataxia is recognized today as a much more extensive disease than it was for a long time supposed to be, and from various indications it appears that the distribution of its lesion will be found in the future to be wider than the facts now warrant us in accepting. Indeed, the implication of many of the motor nerves and tracts would seem to be more than a mere extension of the pathologic process from the contiguous sensory structures. Instead of the disease being a purely systematic one, it begins to resemble an extensive form of multiple sclerosis. The names posterior spinal sclerosis and tabes dorsalis are no longer accurate, for the posterior columns are not the only parts of the sensory cord that are affected, while the process is no longer considered an ordinary form of sclerosis; nor is the disease a genuine tabes, confined solely to the dorsal region.

Without reviewing the development of our knowledge in regard to the parts of the nervous system involved in locomotor ataxia $I$ will simply indicate those that are now known to be affected. They are the columns of Goll and Burdach, including the posterior root-zones of Charcot; the direct cerebellar tracts of Flechsig, which many think are the real cause for the ataxia by cutting off the transmission of sensory impressions to the cerebellum, the organ of co-ordination; the antero-lateral columns of Gowers; the columns of Clarke; and the Spitzka-Lissauer tracts near the circumference of the cord on either side of the posterior roots. Structures outside of the cord that have been found diseased, are the posterior spinal nerve-roots, many of the peripheral sensory nerves, many of the encephalic nerves like the optic, trigeminus, abducens, oculo-motor, auditory and spinal accessory, and parts of the cerebral cortex. 
Of all the extra-spinal lesions, those of the optic and other ocular nerves are the commonest. Out of 1016 cases of optic nerve atrophy observed by Galezowski, 800 were tabetic. The same author noted as a significant prodromic sign of locomotor ataxia, unilateral paralysis of the muscles of accommodation associated with anesthesia of the corresponding periorbital region, unaccompanied by mydriasis. Kayer of Berlin, found impairment of vision in 35 per cent of 117 cases of locomotor ataxia in Mendel's clinic the Argyll-Robertson pupil occurring in 66 per cent. Any number of cases might be cited, all manifesting an early and significant implication of the ocular nerves. The organ of sight, however. does not exhaust all the cranial nerve palsies, and Erb says these cephalic symptoms are present in one-half of all cases of tabes, and are persistent in from one-third to onesixth.

The auditory apparatus comes in for its share of trouble. In the examination of some forty cases, Marini found that only 17.5 per cent. had normal hearing, while 29 per cent. had some affection of the auditory apparatus. Of the latter, 10 per cent. had middle ear disease, and 37.5 per cent. had undoubted internal ear disease, a condition which was also suspected of the remaining cases. Morpurgo observed that forty-three out of fifty-three cases of tabes had some auditory trouble. Admitting that some of these statistics may be open to question, it is none the less true that impairment of hearing, due to true nerve-deafness, as well as to trophic disturbances in the auditory apparatus, is not an uncommon symptom of locomotor ataxia.

The vagus accessorius and glosso-pharyngeal (Oppenheim) have been found degenerated, along with the extension of the spinal lesion up into the corpora restiformia. Many of the bulbar symptoms have been attributed to disease of the central nuclei, but after a careful investigation Van Gieson concludes that the various crises are really due to peripheral and not to central lesions. He reports a case in which a painstaking autopsy revealed, besides the usual characteristic spinal lesions of tabes, a bilateral chronic diffuse neuritis of the vagus and spinal accessory roots, but without involvement of the nuclei of those nerves.

Ever since Déjerine in 1883 described his case of locomotor ataxia in which there was only a general peripheral neuritis, and in which the cord elements and posterior roots were discovered to be normal, the lesions of the peripheral nerves, with or without accompanying spinal cord lesions, have attracted more and more attention until the extreme view has been advanced (Dejerine) that locomotor ataxia is, after all, a disease primarily of the peripheral nerves, a neuro-tabes periphérique. In his own words, Déjerine says that tabes is beginning to present more and more the appearance of a peripheral disease of the sensory and motor, and nerves of special sensation. According to this idea the medullary lesions are the result of a secondary degeneration, and the entire nervous affection is the product of a toxin in the blood.

Leyden, Redlich, Déjerine and Marie have all demonstrated that the primary trouble is in the posterior nerve-roots in their intra-medullary course. Marie sums up these views thus: "The changes found in the tabetic spinal cord are not the results of a primary systematic myelopathy. They are the expression of a progressive degeneration of the posterior root fibers. These medullary changes in tabes occur in segments, while each diseased posterior root furnishes a new contingent of degenerated fibers to the spinal cord." The question which is still unsolved is whether the origin of the degenerative process is below or above the posterior ganglion. The cause of the degeneration in the posterior roots is supposed by Marie to be a disease of the spinal ganglion cells as well as of the peripheral ganglia. Locomotor ataxia therefore resolves itself primarily into a granglionic disease induced by a virus. Wallenberg of Halle, and Ransom give strong support to these views of Marie from postmortem examinations made by themselves. Blocq of Paris adds his confirmation also, and furthermore shows the developmental character of the degeneration of the medial portions of the posterior roots, those portions which are the first to become diseased consisting of thicker fibers and developing very early in embryonic life (from the seventh to the eighth month)

Whether this ganglionic theory be wholly true or not, there must be some place of beginning for the disease process. The usual site of this beginning, and the reason for the disease commencing at this site have been the inspiration of many theories and much controversy. That the extension of the disease is an upward degeneration will not, I presume, be disputed by anyone; for clinical as well as pathologic observa. tion prove it. There is a gradual centripetal disap. pearance of the axis cylinders and medullary sheaths (Adamkiewics) with accompanying neurogliar changes (Schiefferdecker and Homén). It may not be untrue, as some more recent writers have stated, that the progressive scleroses of the spinal tracts are, to a certain extent, primarily attributable to an overgrowth of the neuroglia originating in the epiblast, as well as of the connective tissue derived from the mesoblast; so that as Dana says, we may have to speak of the process as a posterior spinal fibrio-gliosis. At this point the well known conclusions of Déjerine and Letulle are appropriately recalled. The neurogliar type of sclerosis, according to these investigations, is characteristic of Friedreich's disease, and we can therefore understand the hereditary nature of this form of locomotor ataxia, since it has been proved that the neuroglia is histologically of ectodermic origin and not meso-dermic, as is the associated connective tissue. In the neurogliar sclerosis of Friedreich's disease the defect is an embryologic one and not vascular, as it is in the mixed connective tissue type of sclerosis, characteristic of multiple sclerosis, diffuse sclerosis and tabes. The one is an inherited defect, the other an acquired form.

Auscher corroborates these views from an autopsy. According to Tellinek of Vienna, the lesions of the cerebellum found in six cases of tabes, consisted of atrophy of the nerve cells of the dentate body and degeneration of the medullary fibers of the lobules, which to some extent would seem to indicate the parenchymatous nature of the pathologic process.

From past observations the most frequent focus from which the lesions of locomotor ataxia took their start seemed to be in the dorso-lumbar region. Many have been the reasons given to account for this. Long ago, when the lesion was supposed to be of an inflammatory nature (Vulpian, Charcot, Erb), the gravitation and stagnation of the circulation in this part of the cord were advanced as sufficient reasons. Then when sexual excesses were considered as a potent cause of the disease instead of an unfortunate early symp. tom, their disturbing influence upon the local circula- 
tion and over-excitation with exhaustion of the genitospinal centers were blamed for the trouble starting in this region. The vasomotor theory of Porter based upon organic alterations in the anterior and posterior spinal blood vessels, with consequent disturbance of the local nutrition was certainly ingenious, but hardly tenable in view of the wide extent of the lesion and the similar vascular changes in parts of the nervous system not subject to sclerosis and degeneration. The same criticism applies to Spitzka's explanation in regard to the thickly interwoven minute fibrous network in the dorso-lumbar part of Burdach's columns, as being the reason for the disease originating there. Not even the views of Déjerine, founded upon the existence of a local meningitis and neuritis, nor those of Obersteiner and Redlich, based upon the injury supposed to be caused to the posterior nerve roots, by a syphilitic inflammation and contraction of the membranes of the cord surrounding the roots at their exit, are entirely satisfactory. First. locomotor ataxia is a most extensive disease, and not all cases, by a large majority, begin in the dorso-lumbar, or any other region of the cord; and second, if these various local conditions, invoked as an explanation of the origin of the disease in the dorso-lumbar part of the cord be entirely adequate, why do the same conditions not account for those forms of locomotor ataxia that start elsewhere in the cerebro-spinal system, than in the dorso-lumbar region? For example, how can general organic thickening of the vascular walls throughout the body, or local meningitis determine all of the many varied forms of tabes? How can a peculiar histologic network in a certain part of the cord account for cases that ofttimes seem to originate in peripheral nerves? How can gravitation and local stasis be made to answer for such varieties as cervical tabes? For the frequent forms of tabes that have the origin of their lesion in the dorso-lumbar part of the cord, almost any one of these various explanations would answer; but for the other and irregular forms, they are all untenable. In science a theory is not acceptable unless it is capable of being applied to every individual instance of a series. It does not seem to me that any one of these explanations, applicable as they may be for the dorso-lumbar forms of locomotor ataxia, can be applied in those not uncommon instances (Galezowski and others) in which the ocular so long precede the spinal symptoms; in those (Martins, Déjerine, Finny, Weir Mitchell) in which the cervical symptoms predominate; in those (Trousseau, Déjerine, Gubler, Luys) in which only the peripheral nerves seem to be affected. Indeed, no sufficient explanation for the origin of all cases of locomotor ataxia has yet been proposed. Many of the exciting causes such as trauma, local meningitis and sexual excesses operating in conjunction with a neurotic cachexia do determine the original site of the disease process; but for those insidious, apparently spontaneous cases starting from merely a general cachectic condition of the nervous system, there seems to be no explanation. For the selective implication of the sensory elements in these latter cases it appears very much as though we will have to consider some peculiar cellular structure or alteration or differentiation, some histologic peculiarity in the sensory elements themselves as the real determining cause.

As a result of some embryologic investigations made by Trepinski, under the direction of Flechsig, the latter declares that not only in the posterior columns but in the posterior nerve-roots as well, the parts that undergo degeneration first in tabes correspond to certain definite embryologic trants. These tracts are the so-called middle root zones and median zone of the posterior columns. The other fibers from the middle root zone, which in the embryo appear later and seem to go to the columns of Goll, remain intact in tabes. Flechsig's entire article is full of suggestions and seem to point in the right direction for a solution of the question as to the selective action of the cause or causes of locomotor ataxia. Blocq confirms the origin of these tabetic degenerations in certain tracts of the posterior roots, which are developed in the embryo earlier than are some of the adjoining tracts. Can any such differentiation be found between the sensory and motor tracts as to enable us to comprehend why, with such general causes as a blood dys. crasia, locomotor ataxia should always be a disease of the sensory apparatus? It certainly would be a mag. nificent attainment if we could fully and positively assert as Leyden does, quoted by Obersteiner, that locomotor ataxia is "a chronic atrophic degeneration process of the spinal cord, originating in the posterior roots and connecting itself with distinct embryologic fiber symptoms."

$$
\text { BIBLTOGRA PHY. }
$$

Jones: Northwestern Lancet, 1896, xvi.

Marechal: Legons sur les Maladies Nerveuses, 1ìre partie, Brux,, 1896. Weidner: American Theraplst, 1896-97,

bon; Contribution à létude des myélites infect. expérimentales, Paris,

Lamy: Compt. rendu soc. de biol., Paris, 1846, 10 s. $1 \mathrm{i}$

Lanny: Tribune Médieale, Paris, 1897, 2, s. xxix.

Barie: Le coeur chez les tabétiques, Rev. gén. de Clin. et de Thérap., Paris, 1896, $x$.

rennen: Syphilis as cause, etc., Alienist and Neurol., St. Louis, 1886, xvii.

Cleveland Med. Gazette, 1896-7, xii.

Meirowitz: Alcoholism as Cause, Post-Graduate, N, Y., 1896, XI

Raymond: Progres Med., Paris, 1896,3' s. ili.

Pierre: Jour. de la Santé, Paris, 1895, xii.

Bailey: Jour. of Nerv, and Ment. Diseases, N. Y., 1895, xxii.

Diller: Medical Record, N. Y., 1895, xlviii.

Albany Med. Ann., 1895, xvi.

Diller: Westminster Hosp. Reports, London, 1895, ix.

Möbius: Neurologische Beitrüge, Leipzig, No. 3, 95.

Darkschewitsch: La Médecine Moderne, Paris, Dec., 1884

Blathner: Inaugural Dissert., Berlin, 1895.

Minor of Noscow: Neurologische Centralblatt, Leipzig, July, 1892

Grimm: Internat. Klinisehe Rund
Teissier: La Province Med., 1887.

Karger: Inaugural Dissert., Berlin, 1887.

Karger: Inaugural Dissert., Berlin, 1887.

Hutchinson: Med. Press and Circular, London, 1887

Galezowski: La Semaine Médicale, 1888.

Galezowski: La Semaine Medicule, 1888.

Schwarz: St. Petersburger Medicin. Wochenschrift, 1889

Germeix: Arch.le Medecine et de Phar. Militaires, Jan., 1889.

Strümpell: Münehener Medicin. Wochenschrift, Munich, Bept., 1890.

Vermel: Le Progrès Médical, Yaris, Feb., 1890.

Leloir: Journal de Medecine de Paris, Dec., 1889

Erb: London Practitioner, London, Sept., 1891.

Gerlach: Fortschritte der Medicin, Berlin, Feb., 1891.

Bernhardt: Neurologisches Centralblatt, Leipzig, Dec.. 1890.

Guelliot: L'linion Médicale, Paris, No. 2-4, 1882 .

Raymond: Le P'rogrís Alédicale, Paris, Juue, 1892.

Gajkiewicz: Syphilis du systime Nerveux, Paris, 1892

Marie: Legons sur les Maladies de la Moelle, Paris, 1892.

Dana: New York Medical Jourual, Jan. 9, 1892

Lagondaky : Le Bulletin Médical, Paris, July, 1894.

Kuhn: Inaugural Dissert., Berlin, 1894.

Pitres: Quoted by Berens in Thesis, London Lancet, April 13.1895.

Cyden: Quoted by Storbeck in his Inaugural I)issertation, Berlin, 1895. Cardarelli : Gazzetta degli Ospltuli, Naples, 1895

Grasset: Sajous' Annual, 1858

Bramwell: Jiseases of the Spinal Cord.

Déjerine: A rch de Physiologie, 1884 .

Déjerine: Arch, de Physiolo

Bartholow : Practice of Medicine.

Ranney: Lectures on Nervous J)iseases.

Ranney: Applied Anatomy of the Nervous syatem.

Fournier: Atuxie Locomotrice, 1872

Gaskell: Journal of Physiology, vii, p. 1

Mettler: On the Nature of Locomotor Ataxia, Jour. of American Med. Asso., 1894.

ettler: Is locomotor Ataxia a Constitutional Disease Primarily, Ch1 cago Med. Kecorder, 1842

Hadden : Brain, Oct., 1888

Homén: Gontribution Expériment. ì la Path. de la Moelle Finière. HeI singtors, $1 \times 55$.

Brissaud: legons sur les Maladies Nerveuses, Paris, 1895.

Tooth: St. Bartholomew's Hosp. Reports, v, xxi.

Spitzka: Alienist and Neurol., $18 \$ 5$.

Spitzka: Pepper's System of Iledicino.
Gowers: Diseases of the Nervous System. 
Minor: Arch. de Neurologie, March, $18 s 9$.

Langley: Brain, April, 1885 .

Sherrington: Brain, Oct., 1886.

Prince: Jour. nervensystems, Vienua, $1395 \mathrm{~B}$.

Rosenblatt: Inaugural Dissert.. Berlin, 1893.

Gray: Neryous and lental Diseases, Phila., Is93.

Gray. Nervous and Mental Diseases, Phila., 1893 . 1891

Ziemssen's: Cyclopæda of Medicine, N. Y., 1s78.

osler: Practice of Medicine. N. Y.. 1892 .

Hamition: Nervous Diseases. Phila., 1881 .

Roberts: Theory and Practice of Medicine, Phila., 1894.

Topinard: De' J'Ataxie Locomotrice, Paris, 1864.

Kayer: Inalgural Dissert., Berlin, 1887 .
Marini : Arch. für Isychiatrie und Nervenkrankheiten, Berlin, $3,21, \mathrm{H}$.i. Morpurgo: L'Union Yédicale, Paris. July 3, 1890

Oppenheim: Berlin, Klinische Wochenschrift, 18ss, No. 20

Van Gieson: Jour. of Nervous and Ient. Dis., N. Y., Juls, 1890

Déjerine: Arch. de Physiologie, Paris, 1888

Finny: Iondon Lancet. Aug. 11, 1888.

Weir Nitchell: Jour. of Nerv. and Ment. Jis., April, 1888.

Dejerine: La Médecine Moderne, Paris. Mar. 20, 1890

Flechsig: Neurologische Centralblatt, Leipzig, Jan. 15, 1890

Dejerino and letule: La Semaine Jed.. Paris, Mar. 12, 1890

Auscher: La Semaine Méd., July 30,1890

Marie: Iecons sur les Mal. de la Moelle, Paris.

Redlich: Psychiatrische Jahrbücher, v. 11.

Dejerine: La Semaine Med., Paris, Dec. 14, 1892

Marie: Le Prouris Med., Paris, Dec. 24, 1882

(1892.

Ransom: British Medical Journal, Jondon, v. 2, 1802.

Obersteiner: Quoting Leyden in Sajous' Annual, 1893, Vol. 11, p. B. 33. 4544 Lake Ave.

\section{A STUDY OF RETRO-PERITONEAL NEO- PLASMS WITH SPECIAL REFER- ENCE TO DIAGNOSIS.}

Read before the Southern Surgical and Gynecological Association at St. Louis, Mo.

BY RICHARD DOUGLAS, M.D. NASHVILLE, TENN.

Definition.-For the purpose of my paper I accept the limitation suggested by Mr. Lockwood for retroperitoneal neoplasms. The term implies a solid or cystic tumor growing behind the peritoneum, into its folds and not connected with any of the great retroperitoneal organs. So we at once eliminate from our consideration tumors of the kidneys, pancreas, uterus and so-called broad ligament ovarian cysts. Neoplasms connected with any of the retro-peritoneal viscera usually present sufficient evidence in their history, symptoms and physical signs to enable us to ascribe their site of origin.

Origin.-Surgeons are not very careful in determining at the time of operation the true origin of the tumor with which they are dealing. The spirit of the pathologist is for the time eclipsed by the surgical emergencies. Therefore, I feel safe in assuming that many retro-peritoneal neoplasms have been encountered, the surgeon, recognizing the inoperable character of the case or awed by the apparent insurmountable difficultios, abandons the attack and consigns the patient and the diagnosis to oblivion. The structures involved primarily in these growths are the retro-peritoneal cellular and fascial tissue, retro-peritoneal and mesenteric glands, the sheaths of the great blood vessels and the vertebræ.

Pathology.-The type of tumor usually encountered in the retro-peritoneal space belongs to the con. nective tissue group. A careful study of these cases shows that they are of a mixed variety, the predominating type being sarcoma and lipoma, occasionally fibroma and myxoma are seen. An analysis of the twenty cases of solid retro-peritoneal tumors collected by Rogowski showed sarcomatous tissue in every one.

The peculiarity of retro-peritoneal sarcomata is that they are encapsulated. According to Mr. Cripps, they do not recur when removed. From a careful investigation of the literature on this subject I think the speaker was safe in making this assertion inasmuch as about 95 per cent. of the patients die from the operation or before it.

The predominating microscope picture is generally of the spindle cell sarcoma, yet in literature we see such descriptive terms as myxo-sarcoma, lipo-sarcoma, fibro-cysto-sarcoma, otc. Metastasis occurs in about one-half the cases, the liver, lungs and mesenteric glands being the parts involved.

Frequency.-There seems to be a general understanding among surgeons that these tumors are so rare that they are scarcely worth special study, and this is borne out somewhat by Mr. Lockwood, who says that no specimen of retro-peritoneal sarcoma has been exhibited in the Obstetrical and Pathological Society of London, and prior to 1895 the Medical Society of London had no opportunity of discussing this peculiar pathology, yet in 1889 Rogowski was able to collect twenty cases. In a recent discussion in the Royal Medical and Chirurgical Society of London, Mr. Shield reports a very instructive case of retro-peritoneal sarcoma and from the limited discussion that it elicited one would infer that the members were quite unfamiliar with the subject.

Age.-They occur after maturity, from 28 to 59 years. Mudd's patient, the oldest on record was 71 years. In one case reported by Joseph Austein, the patient was a female 4 years of age.

Sex.-These growths occur alike in both sexes.

Duration.--Duration of life history of retro-peritoneal tumors is usually about six months, though some cases have lasted for years, but usually when the tumor has existed for so long a time the original growth was some form of typical neoplasm and sarcomatous change engrafted tupon it. Thus in Waldeyer's case in which the tumor weighed sixty-three pounds, there was some history of abdominal tumor for several years; the microscopic examination showed it to be a lipo-myxo-sarcoma.

Causation.-There is no recognized cause for these growths, yet in some cases. the malignant growth appears as secondary to some local injury or suppuration. Rogowski reports a case of Neumann in which tubercular abscesses occurred some ten years before the appearance of a sarcomatous tumor at the site of suppuration. There has been some effort to assign these growths to specific origin, yet we would scarcely expect a gumma in the loose retro-peritoneal tissue without its occurrence in other organs.

Diagnosis.-The difficulty that surrounds the differential diagnosis of abdominal swellings is notorious, and a solid growth that can not be attributed to any of the great organs should at least aronse suspicion. Clearly it is of the greatest importance that we should learn to diagnose these retro-peritoneal tumors before they have seriously affected the health of the patient, acquired such universal attachments, and distorted the abdominal viscera. And it appears that the diagnosis would be much easier in the early stage if the investigation is made under anesthesia.

Retro-peritoneal tumors possess certain well marked characteristics not found in primary intra-abdominal neoplasms. The latter originate primarily between the duplications of the peritoneum, are attached to the organs from which they spring and have their attachment between the intestines and pelvic cavity, while retro-peritoneal tumors "originate in the retroperitoneal space and as they develop they encroach 